\title{
On establishing coreference in Left Dislocation constructions
}

\author{
Johan Oosthuizen \\ Department of General Linguistics, Stellenbosch University, 7600 Stellenbosch, South Africa \\ E-mail: jo@sun.ac.za
}

\begin{abstract}
The phenomenon of left dislocation (LD) has received relatively little attention in the generative literature. In Government \& Binding theory and early versions of Minimalist Syntax, the leftdislocated expression is conventionally taken to be base-generated in its sentence-initial surface position and the resumptive pronoun in some other position in the structure. The establishment of an (obligatory) coreferential relationship between these expressions is usually ascribed to a special binding mechanism, A-bar binding, though this issue is seldom explicitly addressed in LD studies. The aim of this paper is to present, in broad outline, an alternative analysis of LD constructions, one that incorporates the core hypotheses of the nominal shell analysis of coreferential constructions put forward by Oosthuizen $(2013 a, b)$. On this analysis, the resumptive pronoun and the referring expression that is to serve as its antecedent are basegenerated in a nominal shell structure which is headed by a presentational focus light noun, a functional category belonging to a natural class of identificational elements. The coreferential relationship between the two expressions is established within this structure by means of phifeature valuation. The antecedent is subsequently raised into the left-periphery of the sentence, where it surfaces as the left-dislocated expression. It is claimed that such an analysis can account for the phenomenon of obligatory coreferentiality in LD constructions in terms of formal devices that are either already provided by or compatible with the basic assumptions and concepts of Minimalist Syntax. A tentative proposal is also put forward to account for the word order in LD constructions, specifically for the fact that left-dislocation does not bring about (surface) subject-verb inversion in V2 languages such as Afrikaans.
\end{abstract}

Key words: left-dislocation, coreferential relationship, minimalist syntax, nominal shell, Afrikaans grammar

\section{Introduction}

It is a striking fact of human language that an expression $\mathrm{Y}$ can enter into a coreferential relationship with an expression $\mathrm{X}$ in some other position in a sentence. This phenomenon can be schematically represented as in (1), with the coreferential relationship indicated by means of the shared subscripts.

$$
\left[\ldots X_{i} \ldots Z \ldots Y_{i} \ldots\right]
$$


Coreferentiality is a widespread phenomenon, not only across languages but also across an array of constructions in particular languages. To illustrate, consider the following superficially diverse constructions in Afrikaans. In each case, the pronominal expression in small caps represents an anaphor; that is, it cannot be used on its own to pick out a referent in the real or an imaginary world but is referentially dependent on some other expression in the sentence, its antecedent (given in bold).

(2) Reflexive constructions

Die $\operatorname{man}_{i}$ haat HOMSELFi

the man hate himself

"The man hates himself"

(3) Control constructions

Sandra $_{i}$ weier $\left[\mathrm{om} \mathrm{PRO}_{\mathrm{i}}\right.$ die werk te doen]

Sandra refuse COMP PRO the work to do

"Sandra refuses to do the work"

(4) Possessive constructions

$\boldsymbol{J a n}_{i}$ het $S Y_{i} \quad$ ö̈ geknip

Jan has his eyes blink

"Jan blinked his eyes"

(5) Floating quantifier constructions

Die kinders $_{i}$ sal ALMALi 'n geskenk kry

the children will all a present get

"The children will all get a present"

(6) Relative clause constructions

Ek ken die meisie $_{i} \quad\left[\mathrm{WAT}_{\mathrm{i}}\right.$ jy genooi het]

I know the girl who you invite have

"I know the girl who(m) you invited"

(7) Reciprocal constructions

Die kandidate $_{i}$ het MEKAAR $\mathrm{i}_{\mathrm{i}}$ beledig

the candidates have each-other insult

"The candidates insulted each other"

(8) Left-dislocation constructions

Daardie $\operatorname{man}_{i}$, ek vertrou $\mathrm{HOM}_{\mathrm{i}}$

that man I trust him

"That man, I trust him" 
Constructions such as those in (2)-(8) (which may be called "coreferential constructions” for ease of reference) raise the following questions: ${ }^{1}$

a. What is the function of the particular construction?

b. What is (i) the underlying structure and (ii) the derived structure of the particular construction?

c. How can the coreferential relationship expressed in the construction be accounted for?

This paper addresses the questions in (9) as they relate to left-dislocation (LD) constructions such as the one illustrated in (8) above. Adopting the theoretical framework of Minimalist Syntax, ${ }^{2}$ the aim is to outline an analysis of LD constructions that incorporates three main hypotheses. The first states that the anaphoric expression in such a construction - e.g. hom ("him") in (8), conventionally referred to as a "resumptive pronoun" - and its antecedent - e.g. the referring expression daardie man ("that man") in (8) - have a common structural origin. More specifically, these expressions are initially merged into a nominal shell structure that is headed by a presentational focus light noun, a functional category belonging to a natural class of identificational (or quantificational) elements (see section 3). The referring expression enters the derivation with valued phi $(\varphi)$-features (i.e. person, number, gender), whereas those of the light noun and the resumptive pronoun are initially unvalued. According to the second hypothesis, the referring expression (daardie man in the example at hand) values the $\varphi$-features of the resumptive pronoun, with the light noun acting as intermediary. The third hypothesis states that the $\varphi$-valued resumptive pronoun in the shell structure headed by the specific light noun is semantically interpreted as obligatorily coreferential with the referring expression. In short, the coreferential relationship between the resumptive pronoun and its antecedent is established within a light noun shell structure through $\varphi$-feature valuation. In the course of the derivation, the expression serving as antecedent for the resumptive pronoun is raised into the left-periphery of the sentence, where it surfaces as the left-dislocated expression. It is claimed that such an analysis can account for the phenomenon of obligatory coreferentiality in LD constructions in terms of formal devices that are either already provided by or compatible with the basic assumptions and concepts of Minimalist Syntax.

\footnotetext{
${ }^{1}$ Essentially the same questions are raised by constructions such as those in (i) and (ii) below. Although not coreferential in nature, these constructions illustrate some sort of grammatical dependency relationship between the expressions in bold, with the expletive expression on the left serving as a "place holder" for the expression on the right.
}

Expletive daar ("there") constructions

Daar wag iemand vir jou in die kantoo (vs. Iemand wag vir jou in die kantoor.) there wait someone for you in the office

"There is someone waiting for you in the office"

(ii) Extraposition constructions

$\begin{array}{llllll}\text { Dit is waar } & \text { [dat die aarde rond is] (vs. Dat die aarde rond is, is waar.) } \\ \text { it } & \text { is true that the earth round is }\end{array}$

"It is true that the earth is round"

${ }^{2}$ Cf. e.g. Chomsky (1995, 2000, 2004, 2005a, 2005b, 2006); Hornstein (2009); Hornstein, Nunes and Grohmann (2005); Marantz (1995); Radford (2009). 
Before outlining the proposed nominal shell analysis, however, brief attention is given in section 2 to an alternative approach, one that has been widely adopted in the generative literature since LD constructions were first systematically described by Ross (1967). On this approach, the resumptive pronoun and its antecedent do not share a common structural origin. Rather, the left-dislocated expression is base-generated in its surface position in the leftperiphery of the sentence and the resumptive pronoun in some other position lower down in the structure. The coreferential relationship between these expressions is usually assumed to be established by some sort of binding principle, although this issue is seldom explicitly addressed in LD studies taking this separate origins approach. It must be emphasised, though, that the remarks in section 2 are intended as no more than background for the nominal shell analysis of LD constructions outlined in section 3.

\section{The separate origins approach}

Up to the late 1990s, the phenomenon of left-dislocation received relatively little attention in the generative literature. ${ }^{3}$ In Government \& Binding (GB) theory, the dominant model in the 1980s and early 1990s, most of the attention was focused on the differences between LD constructions and focalisation constructions. ${ }^{4}$ A salient structural difference is that focalisation constructions lack a resumptive pronoun whereas such a pronoun is characteristic of LD constructions, as shown by the English examples in (10). Also, in V2 languages left-dislocation does not bring about subject-verb inversion, in contrast to focalisation and wh-question formation, as illustrated by the Afrikaans examples in (11)-(13).
a. That man she didn't recognise
b. That man, she didn't recognise HIM

a. Daardie man ken sy goed that man know she well "That man she knows well"

b. *Daardie man sy ken goed

\author{
(focalisation)
(left-dislocation) \\ (focalisation)
(left-dislocation)
}

(focalisation)

a. Watter man ken sy goed? (wh-question) which man know she well "Which man does she know well?"

b. *Watter man sy ken goed?

\footnotetext{
${ }^{3}$ Cf. the contribution by Van Riemsdijk in Anagnostopoulou, Van Riemsdijk and Zwarts (1997) for an overview of early analyses of left-dislocation within the generative framework.

${ }^{4}$ For GB theory, cf. e.g. Chomsky (1981, 1982, 1986); Haegeman (1994); Hornstein et al. (2005); Webelhuth (1995). Note that focalisation constructions were commonly referred to as topicalisation constructions in the GB literature.

${ }^{5}$ Note that (13b) would be fully acceptable as an LD yes/no question.
} 
As far as function is concerned, focalisation is generally taken as a means to draw attention to (or to place emphasis on) new information that is presented in the communication context, i.e. information that was not available in the preceding discourse. ${ }^{6}$ In contrast, the function of LD is not to draw attention to new information, but rather to bring the (already known) topic of the following utterance - that which the rest of the sentence is about - to the fore, to make it manifest in the mind of the hearer.

It was claimed in GB theory that focalisation constructions are derived by means of a fronting operation, where the focalised expression is moved out of its base position into its surface sentence-initial position under the CP, leaving behind a copy (or trace) of itself in the position from which the movement takes place. In the case of LD constructions, however, the leftdislocated expression is base-generated in its sentence-initial position - i.e. no movement takes place - which means that this expression and the resumptive pronoun enter the derivation in structurally unrelated positions; syntactically, they have different origins. ${ }^{7}$ As with focalised expressions (and fronted wh-phrases), the sentence-initial surface position of a base-generated left-dislocated expression is situated under the CP. The CP thus contributes to pragmatically contextualise the sentence (or more precisely, a subpart of the sentence). These ideas about the derivation of focalisation and LD constructions are still generally assumed in the generative literature.

In GB theory, and also in earlier versions of Minimalist Syntax, the CP was claimed to consist of three components: (i) a head C (in English, phonetically realised by a complementiser such as that or if but phonetically empty in main clauses); (ii) a complement of the C, taken to be a Tense Phrase (TP) (or Inflection Phrase (IP) in earlier models); and (iii) an optional specifier of the $\mathrm{C}$, which represents the base-position for a left-dislocated expression or the landing site for a focalised expression or a fronted wh-phrase. Schematically:

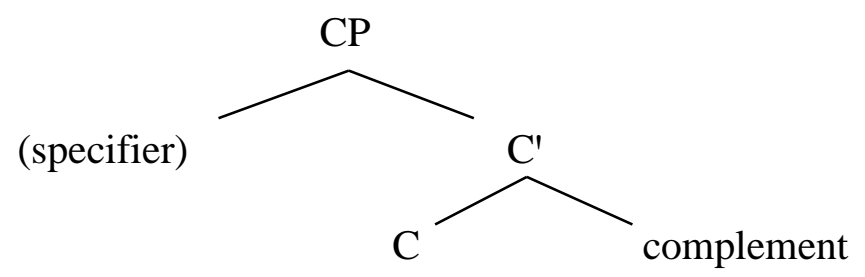

It became increasingly clear that this conception of the CP could not be maintained. To mention just one empirical shortcoming, note that the structure in (14) provides for a single specifier position. However, as shown by the following Afrikaans examples, the left periphery of a sentence can contain more than one expression:

left-dislocated expression + focalised expression

Daardie man, hom ken ek goed

that man him know I well

"That man, him I know well"

\footnotetext{
${ }^{6} \mathrm{Cf}$. the references in footnotes 15 and 16.

${ }^{7}$ Though cf. e.g. Cinque (1977) for an early analysis favouring a movement approach to left-dislocation.
} 
left-dislocated expression + wh-phrase

Die loodgieter, wanneer gaan hy kom?
the plumber when go he come "The plumber, when will he come?"

left-dislocated expression + left-dislocated expression + wh-phrase

$\begin{array}{lllllll}\text { Jou pa, sy paspoort, waar het hy } & \text { dit verloor? } \\ \text { your father his passport } & \text { where has } & \text { he } & \text { it lose }\end{array}$

"Your dad, his passport, where did he lose it?"

In order to overcome the various empirical and theoretical shortcomings of the CP structure in (14), Hoekstra and Zwart (1994) proposed decomposing the C head into two distinct heads, Wh and Top. Instead of a single CP, the left periphery thus comprises two distinct projections, WhP and TopP, which means that there are potentially two specifier positions available. However, this proposal still fails to account for sequences of more than two expressions in the leftperiphery, as illustrated in (17). ${ }^{8}$

Rizzi (1997) subsequently put forward a more refined structure of the left-periphery of a clause (generally known as the split-CP hypothesis), where the $\mathrm{C}$ is decomposed into four functionally distinct heads, each with its own projection: Force, Topic, Focus, and Finiteness. The structural relationships among these heads can be represented as in (18) below (where the asterisks indicate recursivity). In effect, this approach contributes to a "pragmatisation" of syntax. In Rizzi's (1997:283) words, “... we expect the C system to express at least two kinds of information, one facing the outside [i.e. discourse-relevant - JO] and the other facing the inside [i.e. syntactically-relevant - JO].”

$$
\left[\text { ForP } \left[\text { TopP }{ }^{1 *}[\text { FocP }[\text { TopP } 2 *[\text { FinP }[\text { TP ...]]]]]] }\right.\right.
$$

In this schema, the specifier of the TopP ${ }^{1}$ represents the position for a base-generated leftdislocated expression (where the latter provides information that is known from the previous discourse), whereas the specifier of the FocP represents the landing site for a fronted wh-phrase (which signals new information, not known from the previous discourse). Rizzi's approach whereby a conventional category (such as C) is split into a set of smaller, functionally distinct head categories has since been developed into an influential research enterprise in the broad field of generative grammar, known as the Cartographic Approach. ${ }^{9}$

In view of several empirical and theoretical considerations, Beninca' and Poletto (2004) proposed an adapted version of Rizzi's split-CP hypothesis in (18).$^{10}$ In short, they propose, firstly, a non-recursive analysis of Topic, suggesting instead that Topic does not represent a single, undifferentiated head but a "field" comprising several distinct heads, including Hanging Topic and Left-Dislocation. ${ }^{11}$ Secondly, Topic and Focus are claimed to occur in a fixed hierarchy, with Topic above Focus, thus implying that the $\mathrm{TopP}^{2}$ component in (18) is discarded. Thirdly, like Topic, Focus is analysed as a field comprising three distinct heads,

\footnotetext{
${ }^{8}$ It should be noted that Hoekstra and Zwart (1994) do not address the phenomenon of LD.

${ }^{9}$ Cf. e.g. Belletti and Cinque (2004), Benincà and Munaro (2010); Cinque (2002); Cinque and Rizzi (2010), Rizzi (2004); Shlonsky (2010); Van Gelderen (2013).

${ }^{10}$ Cf. also Paoli (2006).

${ }^{11}$ Two other heads in the Topic field are List Interpretation and Scene Setting.
} 
namely Informative Focus and two Contrastive Focus heads. On this proposal, a left-dislocated expression is base-generated in the specifier position of one of the Topic-related heads Hanging Topic or Left-Dislocation, whereas a fronted wh-phrase occupies the specifier position of the Informative Focus head. ${ }^{12}$

In summary, in GB theory and earlier versions of Minimalist Syntax, and also in the Cartographic Approach, provision is made for a specific position for left-dislocated expressions within the set of functional categories comprising the left-periphery (i.e. the $\mathrm{C}$ domain) of a sentence. A common feature of these frameworks is that a left-dislocated expression is basegenerated in its surface position in this domain, and is semantically associated with a resumptive pronoun lower down in the structure. However, in most (if not all) of these approaches the question in (9c) is not explicitly addressed: How can the coreferential relationship between a left-dislocated expression and the resumptive pronoun be accounted for? Within GB theory the relationship between an anaphor and its antecedent is established by means of a binding principle, with the antecedent occurring in an argument (A) position, e.g. the subject or direct object position. ${ }^{13}$ In the frameworks outlined above, however, the left-dislocated expression is base-generated in a non-argument (A-bar or $\bar{A}$ ) position in the $\mathrm{C}$ domain, which means that the GB binding principle for anaphors cannot be invoked to establish the coreferential relationship between the resumptive pronoun and its antecedent. Accordingly, those studies that do address the binding relationship between an expression in the $\mathrm{C}$ domain (e.g. a fronted focus expression or wh-phrase) and an element lower down in the structure (e.g. the copy (or trace) of the fronted expression) typically adopt an additional binding mechanism in the form of $\bar{A}$-binding. Such a mechanism is not required in the proposed nominal shell analysis of LD constructions, to which we now turn.

\section{The common origin approach}

Oosthuizen (2013a) put forward an analysis - the nominal shell analysis (NSA) - that attempts to provide a unifying account of the (obligatory) coreferential relationships evidenced in four diverse constructions in Afrikaans, namely reflexive constructions (illustrated in (2) above), control constructions (3), possessive constructions (4), and floating quantifier constructions (5). ${ }^{14}$ Such an analysis has also been worked out for relative clause constructions in Afrikaans (6) by Meyer (2015). The aim of the present section is to describe, in broad outline, an analysis of LD constructions in terms of the core hypotheses of the NSA, focusing specifically on the coreferential relationship between the left-dislocated expression and the resumptive pronoun.

A basic hypothesis of the NSA is that two expressions which enter into an obligatory coreferential relationship are initially merged into a nominal shell structure that is headed by a light noun $n$, a functional category belonging to a natural class of identificational (or quantificational) elements. It is argued in Oosthuizen (2013a) that this class includes at least

\footnotetext{
${ }^{12}$ Cf. Botha and Oosthuizen (2009) for an analysis of the left-periphery in Afrikaans in terms of the proposals put forward by Rizzi (1997) and Beninca' and Poletto (2004).

${ }^{13}$ For GB Binding theory, cf. e.g. Chomsky (1981, 1982, 1986), Chomsky and Lasnik (1993, in Chomsky 1995); and Reinhart and Reuland (1993).

${ }^{14}$ Oosthuizen (2013:138-144) argues that such an analysis can also account for the grammatical dependency relationship in Afrikaans expletive daar ("there") constructions as illustrated in fn. 1. Cf. also Msaka (2014), Visser (2015) and Elghariani (2016) for nominal shell analyses of reflexive and control constructions in Chichewa, Mihavani, and Tripolian Libyan Arabic, respectively.
} 
the light noun types listed below; from an information structure perspective, each contributes to the interpretation of a particular sentence:

- $\quad$ an identity focus light noun, which occurs in constructions that are used to draw attention to (or emphasise) the relationship of referential identity between two expressions (e.g. in obligatory reflexive constructions);

- a possessor focus light noun, which occurs in constructions that are used to assert the identity of the entity representing the possessor in a possessor-possessee relationship;

- a quantity focus light noun, which occurs in constructions that are used to bring the quantity of a set of entities into focus (e.g. in floating quantifier constructions);

- a contrastive focus light noun, which occurs in constructions that are used to identify or emphasise one entity from a set of (explicitly stated or contextually implied) alternatives for which a proposition holds true; ${ }^{15}$ and

- a presentational focus light noun, which occurs in constructions that are used to signal the introduction of a particular referent into the discourse (e.g. in expletive constructions). ${ }^{16}$

Against this background, consider again the LD construction illustrated by the Afrikaans example in (8), repeated here as (19):

\section{Daardie man $_{i}$, ek vertrou $\mathrm{HOM}_{\mathrm{i}}$ that man I trust him "That man, I trust him"}

In terms of the nominal shell hypothesis stated above, the left-dislocated expression daardie man ("that man") and the resumptive pronoun hom ("him") in (19) are initially merged into the light noun shell structure in (20). The head of this shell is taken to be a presentational focus light noun, pres- $n$, containing the feature [pres-focus]. In this structure, pres- $n$ takes the resumptive pronoun as its complement and the referring expression daardie man as its specifier. Note that the latter is also analysed as a light noun phrase, one that is headed by an $n$ which is distinct from the pres- $n$ and which contains a discourse-related [topic] feature. ${ }^{17}$ Crucially, unlike the $n \mathrm{P}$ daardie man, the resumptive pronoun and the pres- $n$ are both unvalued for $\varphi$ features (person, number, gender) when they enter the derivation. ${ }^{18}$

\footnotetext{
${ }^{15}$ For contrastive focus, cf. e.g. Rochemont (1986); Rochemont and Culicover (1990); É. Kiss (1998); Gundel (1999); Roberts (1998); Kenesei (2005). Cf. also Drubig and Schaffar (2001) and Gundel and Fretheim (2004).

${ }^{16}$ For presentational focus, cf. e.g. Ward and Birner (2001); Erteschik-Shir (2007); Hartmann (2008); Cruschina (2012). Cf. also the references in footnote 15.

${ }^{17}$ Following Chomsky (2006:17-18), it is assumed here that all definite nominal expressions are $n \mathrm{Ps}$, that is, phrases headed by a light noun. This means that the subject $e k$ ("I") in (19) would also be analysed as an $n P$. Cf. also Oosthuizen (2013a:38-39).

18 The resumptive pronoun represents both the minimal and the maximal projection of the phrase it heads (i.e. D = DP), hence the use of the label D/DP in the structure in (20). This structure is simplified in two respects. Firstly, whereas the pres- $n$ (and its projections) and the D/DP both contain (unvalued) case and theta ( $\theta$ )-features (i.e. [ucase] and [u- $\theta]$ ), these features are not indicated under the $n \mathrm{P}$ specifier of the pres- $n$. The reason for this is because it is not entirely clear how these features should be dealt with in the case of left-dislocated expressions (see section 4 for some suggestions). For a discussion of case and $\theta$-features and the manner in which they are valued in the derivation of constructions such as those in (2)-(5) and expletive daar ("there") constructions, cf. Oosthuizen (2013a,b). Secondly, in line with the analyses of coreferential constructions in Oosthuizen (2013a,b), it is likely that the D/DP in (20) undergoes head-to-head raising to the pres- $n$. For ease of presentation, this operation is not indicated in (20) and subsequent structures.
} 


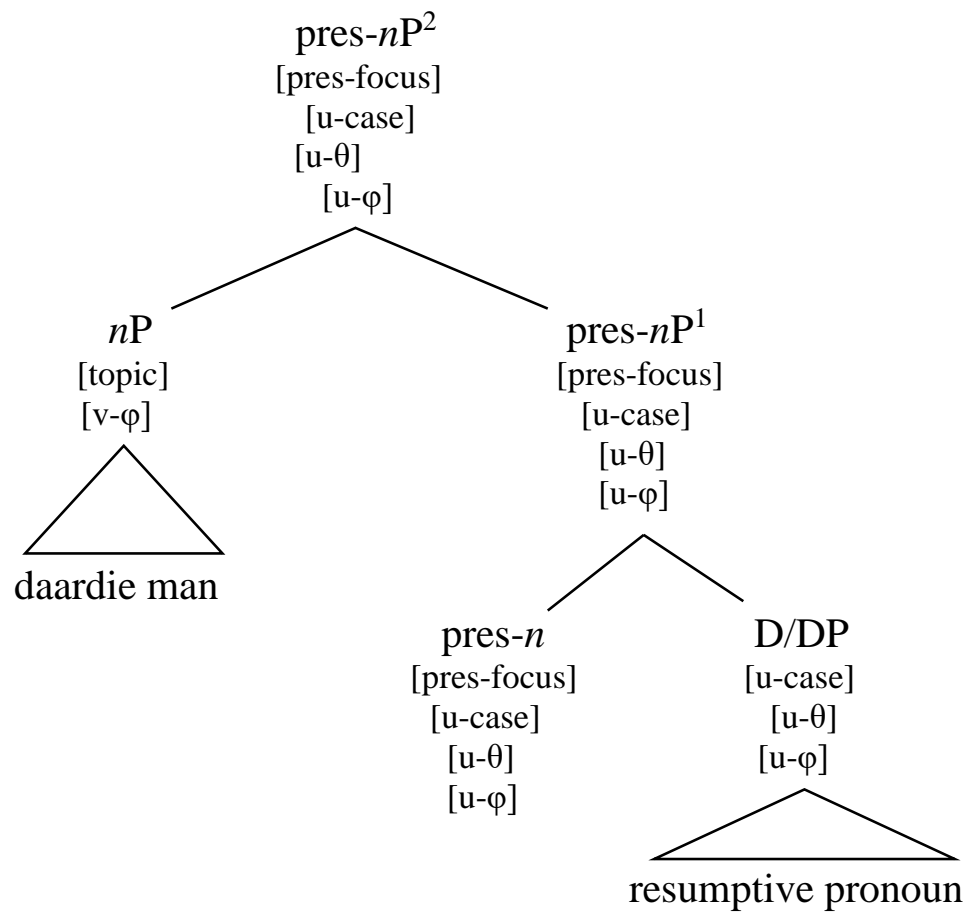

In this structure, the valued $\varphi$-features $([\mathrm{v}-\varphi])$ of the $n \mathrm{P}$ daardie man $\left(3^{\text {rd }}\right.$ person, singular, masculine) serve to value the initially unvalued $\varphi$-features ([u- $\varphi]$ ) of the pres- $n$ head and its two projections pres- $n \mathrm{P}^{1}$ and pres- $n \mathrm{P}^{2}$. As a consequence, the derivationally valued $\varphi$-features of the pres- $n$ can value those of the resumptive pronoun, resulting in the latter being spelled out as hom (abstracting away from the effect of case in this spelling-out operation; see below). In short, the $n \mathrm{P}$ daardie man values the $\varphi$-features of the resumptive pronoun, with the pres- $n$ serving as mediator. The various $\varphi$-valuation operations are indicated by the arrows in (21); features that are valued in the course of the derivation are underlined.

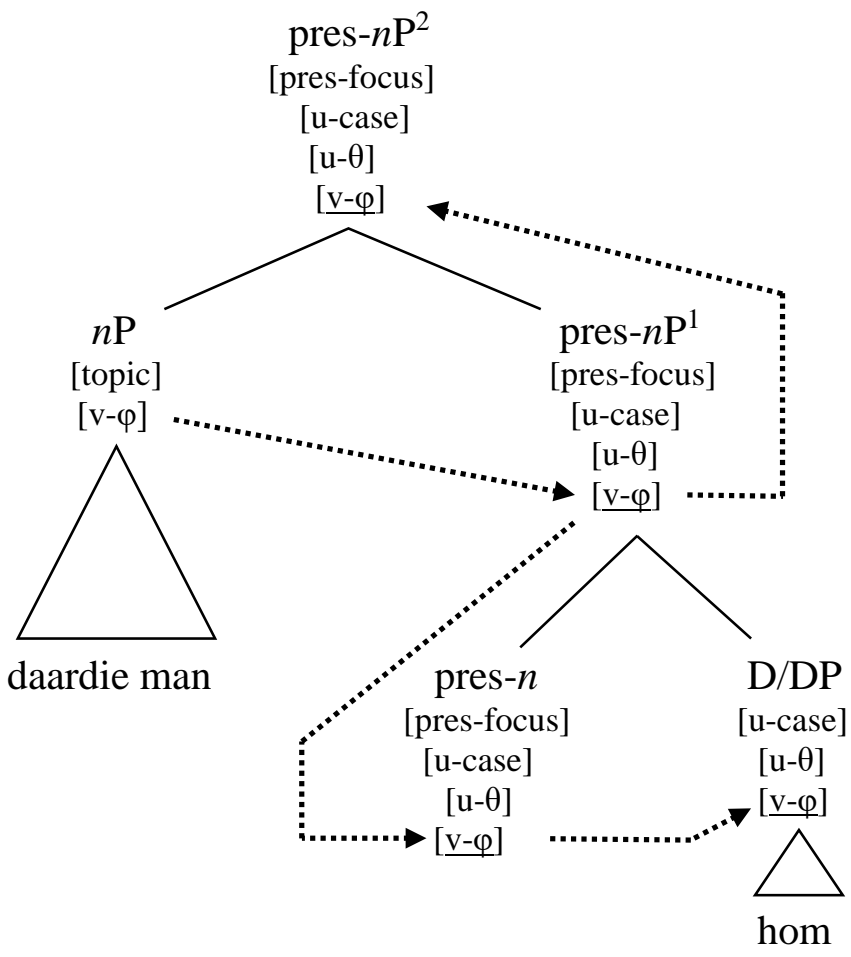


A core hypothesis of the NSA is that, in a shell structure headed by a specific light noun, the (derivationally) $\varphi$-valued pronominal expression which is initially merged as the complement of the light noun is semantically interpreted as obligatorily coreferential with the referring expression in the specifier position of the light noun phrase. In the pres- $n \mathrm{P}$ configuration in (21), the pronoun hom is accordingly interpreted as an anaphor that takes the expression daardie man as its antecedent. Note that this interpretation follows solely from the fact that the resumptive pronoun and its antecedent occur in the particular configuration in (21) and have identically valued $\varphi$-features. As Oosthuizen (2013a:45) states with reference to the establishment of obligatory reflexivity, "the semantic device that is responsible for providing the coreferential (or anaphoric) interpretation has no way of 'knowing' that the $\varphi$-features of the pronoun were (indirectly) valued by its antecedent in the course of the derivation.”

A detailed account of the remaining stages in the derivation of the sentence in (19) falls outside the scope of this paper. Instead, the main steps are briefly outlined below to give an idea of the various operations that are involved in raising the $n \mathrm{P}$ daardie man in (21) to a position in the $\mathrm{C}$ domain, where it surfaces as the left-dislocated expression. ${ }^{19}$

(22) The verb vertrou selects the pres- $n \mathrm{P}^{2}$ in (21) as its object complement, and provides this $n \mathrm{P}$ with the theme $\theta$-value.

(23) The VP which is formed in (22) is merged with an experiencer light verb, and V-to- $v$ raising takes place. ${ }^{20}$

(24) The $v$ enters into an agreement relation with the object complement of the $V$, i.e. the pres- $n \mathrm{P}^{2}$. This entails that the $v$ gets its (initially unvalued) $\varphi$-features valued by the pres- $n \mathrm{P}^{2}$ and in turn provides this $n \mathrm{P}$ with the accusative case value. The $v$ 's $\varphi$-features carry a movement diacritic which triggers raising of the pres- $n \mathrm{P}^{2}$; this is a pied-piping operation resulting in the entire VP ending up in the specifier position of the $v \mathrm{P} .{ }^{21}$

(25) The subject $n \mathrm{P} e k$ is merged into the second specifier position of the $v \mathrm{P}$, where it receives the experiencer $\theta$-value from the $\mathrm{V} / \mathrm{v}$.

The result of the merge and raising operations in (22)-(25) may be represented in the form of the highly simplified structure in (26). For ease of presentation, the various features and valuation operations are not indicated; copies left behind by raising operations are shown in outline font.

\footnotetext{
19 The description given below of the various derivational stages is primarily based on the proposals about word order and linearisation put forward by, amongst others, Biberauer, Holmberg and Roberts (2008), Biberauer and Richards (2006), Biberauer and Roberts (2010), and Roberts (2010). Cf. Oosthuizen (2013a,b) for the application of these and related proposals in the analysis of several (coreferential) constructions in Afrikaans.

${ }^{20}$ For V-to- $v$, cf. Oosthuizen (2013a:ch. 3, note 34) and the references cited there.

${ }^{21}$ Cf. Biberauer et al. (2008) for the notion 'movement diacritic'.
} 


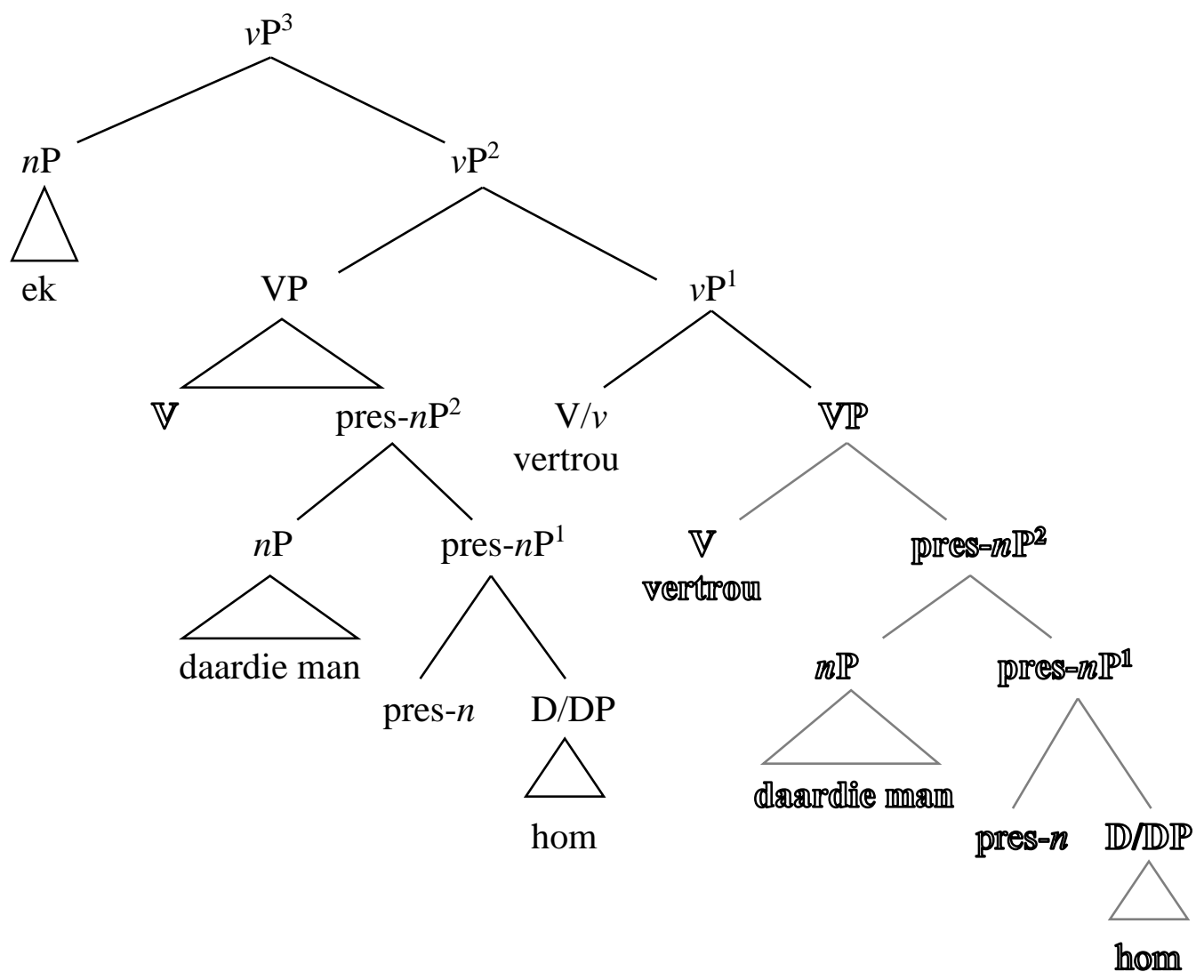

(27) The next step in the derivation involves merging the $v \mathrm{P}^{3}$ in (26) as the complement of a $\mathrm{T}$ head containing, amongst others, the valued features [pres(ent)-tense] and [nom(inative)-case] and a set of unvalued $\varphi$-features [u- $\left.\varphi^{\wedge}\right]$ (where $\wedge$ represents a movement diacritic). The T values the initially unvalued tense feature of the $v / \mathrm{V}$ as well as the unvalued case feature of the subject $n \mathrm{P} e k$. This $n \mathrm{P}$ in turn serves to value the $\varphi$ features of the T. The movement diacritic associated with the T's $\varphi$-features triggers raising of the $n \mathrm{P} e k$, with pied-piping resulting in the containing $v \mathrm{P}^{3}$ ending up in [spec, $\mathrm{T}]$. The resulting structure may be roughly represented as in (28) overleaf.

The final steps in the derivation of (19) all concern the C domain of the sentence. As pointed out in section 2, this domain is generally taken to be the locus of various discourse-related features, each associated with a specific head. It is not clear, however, which of these elements are involved in the derivation of the surface word order of the sentence in (19). The possibilities outlined below are based on the proposals put forward by Rizzi (1997) and Beninca' and Poletto (2004), but are presented here as no more than working hypotheses that require further investigation.

(29) The $\mathrm{TP}^{2}$ in (28) is merged as the complement of a Fin(iteness) head, the lowest category in Rizzi's (1997) expanded C system. V/v-to-Fin raising takes place, yielding a structure with the verb occupying the leftmost position: [FinP vertrou [тр${ }^{2}$ ek daardie man hom ]]. ${ }^{22}$

\footnotetext{
${ }^{22}$ In Afrikaans, V/v-to-Fin only takes place in main clauses and in subordinate clauses that are not introduced by an overt complementiser such as dat (“that”) or of (“if”); cf. Oosthuizen (2013a:54-55).
} 


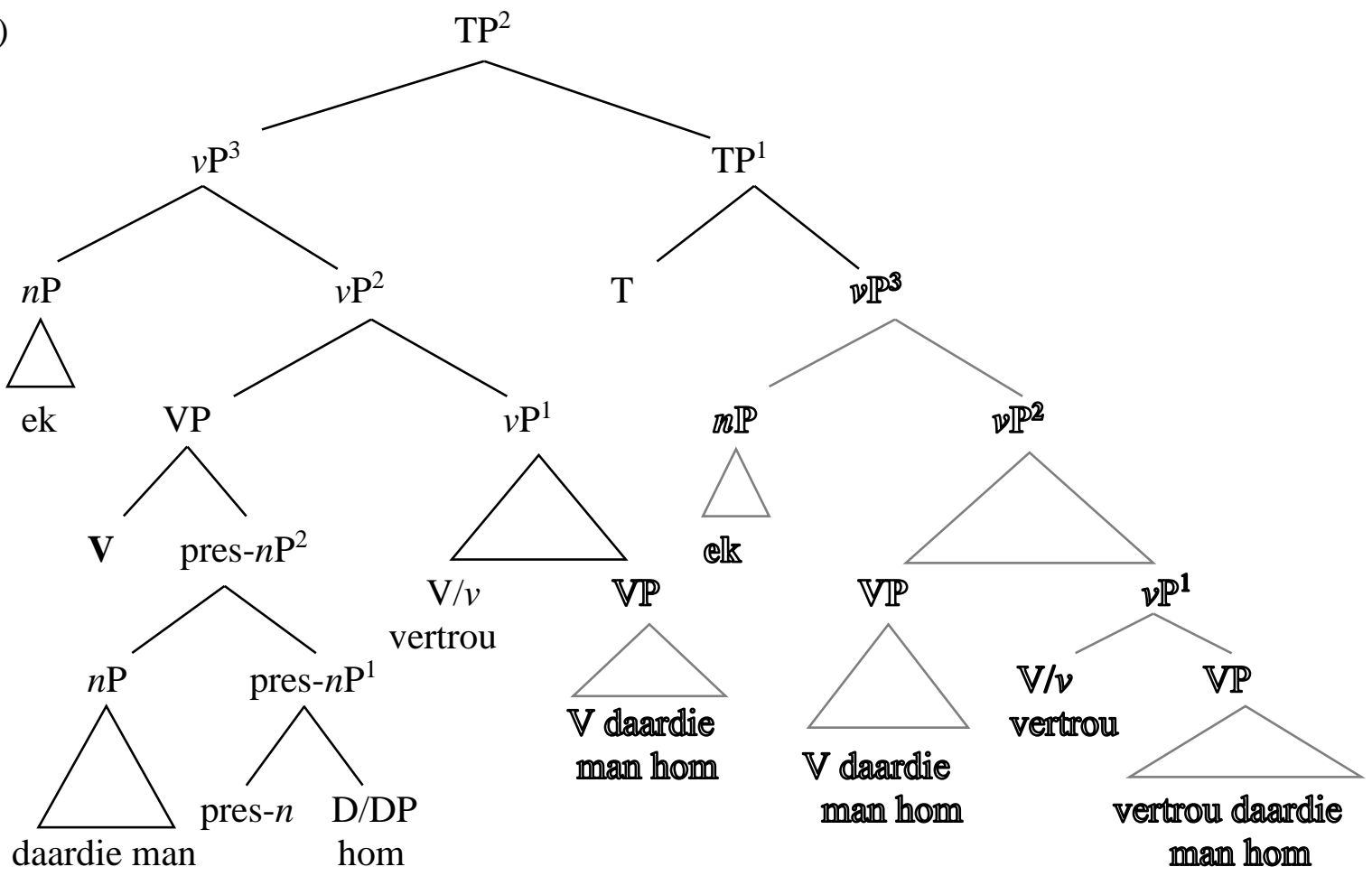

(30) The FinP in (29) is merged as the complement of the Topic ${ }^{2}$ head in Rizzi's (1997) framework (or of the lowest Topic head in the Topic field posited by Beninca' \& Poletto (2004)). The subject $n \mathrm{P} e k$ in the specifier position of the $v \mathrm{P}^{3}$ in (28) is raised into the specifier position of the phrase headed by this Topic category. This results in the structure [ $\mathrm{TopP}^{2} e k$ [FinP vertrou [ $\mathrm{TP}^{2}$ daardie man hom ]]].

(31) Finally, the TopP ${ }^{2}$ in (30) is merged as the complement of the Topic ${ }^{1}$ head in Rizzi's hierarchy (or of the next higher Topic head in Beninca' \& Poletto's (2004) Topic field). The $n \mathrm{P}$ daardie man in the specifier position of the pres- $n \mathrm{P}^{2}$, which itself forms part of the $v \mathrm{P}^{3}$ in (28), is raised into the specifier position of this higher Topic head, where it surfaces as the left-dislocated expression. The resulting structure reflects the surface word order of the sentence in (19): [ $\mathrm{TopP}^{1}$ daardie man [ $\mathrm{TopP}^{2} e k$ [FinP vertrou $\left[\mathrm{TP}^{2}\right.$ hom ]]]].

\section{Summary}

The phenomenon of left-dislocation has received relatively little attention in the generative literature. In GB theory and early versions of Minimalist Syntax, and also in the Cartographic Approach, the left-dislocated expression is conventionally taken to be base-generated in its sentence-initial surface position located in the $\mathrm{C}$ domain of of the sentence. The establishment of an (obligatory) coreferential relationship between this expression and the resumptive pronoun is furthermore usually ascribed to a special binding mechanism, $\bar{A}$-binding, although this issue is seldom explicitly addressed in LD studies. The aim of this paper was to present, in broad outline, an alternative analysis of LD constructions, one that incorporates the core hypotheses of the nominal shell analysis of coreferential constructions put forward by Oosthuizen (2013a,b). In terms of the proposed analysis the left-dislocated element and the resumptive pronoun have a common structural origin. More specifically, they are base- 
generated in a nominal shell structure that is headed by a presentational focus light noun. In this structure, the obligatory coreferential relationship between the resumptive pronoun and the referring expression that is to serve as its antecedent is established through $\varphi$-valuation. More specifically, the referring expression values the $\varphi$-features of the resumptive pronoun, with the light noun acting as intermediary. In the resulting configuration, the resumptive pronoun is interpreted as an anaphor that takes the referring expression as its antecedent. In the course of the derivation the latter is raised into a position in the $\mathrm{C}$ domain, where it surfaces as the leftdislocated expression. In adopting such a raising approach, the nominal shell analysis differs markedly from conventional analyses which favour a non-movement approach to leftdislocation.

An obvious advantage of the LD analysis outlined in section 3 is that it can account for the establishment of an obligatory coreferential relationship between a left-dislocated expression and a resumptive pronoun, and can do so in terms of theoretical devices that are either provided by or compatible with the basic assumptions and concepts of Minimalist Syntax. Specifically, it does not require any special binding mechanism of the type associated with GB theory. Although highly speculative, the ideas briefly outlined in (29)-(31) also seem to provide the basis for an account of the word order in LD constructions, specifically the fact that leftdislocation does not bring about (surface) subject-verb inversion in V2 languages such as Afrikaans. Moreover, these ideas seem to be compatible with the proposals about an expanded C domain put forward by cartographic linguists such as Rizzi (1997) and Beninca' and Poletto (2004).

There are, however, several non-trivial issues that remain unclear. For instance, it needs to be established what the argument status of a left-dislocated expression is and, if it is indeed an argument, which $\theta$-value it is assigned and by which means. One possibility is that such an expression does not in fact represent an argument, which implies that it lacks a $\theta$-feature which has to be valued in the course of the derivation. ${ }^{23}$ Furthermore, it is not clear exactly how (and which) case is assigned to a left-dislocated expression. The analysis outlined in section 3 does not provide for a distinct functional category that can value the case feature of such an expression. For example, in the derivation of the sentence in (19) there are only two casevalueing categories, namely the $T$ (which values the subject's case feature as nominative) and the light verb (which assigns accusative case to the resumptive pronoun). One possiblility is that the left-dislocated expression is not derivationally valued for case, but that it has inherent case. Alternatively, it could be argued that the left-dislocated expression is assigned a default case value (nominative in Afrikaans), perhaps by a mechanism in the phonological component. ${ }^{24}$ These and other issues noted in the course of the discussion are left as topics for further investigation.

\section{References}

Anagnostopoulou, E., H. Van Riemsdijk and F. Zwarts. (Eds.) 1997. Materials on Left Dislocation. Amsterdam: John Benjamins.

Belletti, A. and Cinque. 2004. Structures and Beyond. New York: Oxford University Press.

\footnotetext{
${ }^{23}$ Such an analysis is proposed for the expletive expression daar ("there”, see footnote 1) by Oosthuizen (2013: 138-144).

${ }^{24}$ Cf. e.g. McFadden (2007) and the references cited there for the notion 'default case'.
} 
Beninca', P. and C. Poletto. 2004. Topic, focus and V2: Defining the CP sublayers. In L. Rizzi (Ed.). The Cartography of Syntactic Structures (Vol. 2). The Structure of CP and IP. New York: Oxford University Press.

Beninca', P. and N. Munaro. (Eds.) 2010. Mapping the Left Periphery. New York: Oxford University Press.

Biberauer, T., A. Holmberg and I. Roberts. 2008. Disharmonic word-order systems and the Final-over-Final-Constraint (FOFC). In A. Bisetto and F. Barbieri (Eds.) Proceedings of XXXIII Incontro di Grammatica Generativa. Available online at: http://amsacta.cib.unibo.it/ archive/00002397/01/PROCEEDINGS_IGG33.pdf.

Biberauer, T. and M. Richards. 2006. True optionality: When the grammar doesn't mind. In C. Boeckx (Ed.) Minimalist Essays. Amsterdam: John Benjamins Publishing Company. pp. 35-67.

Biberauer, T. and I. Roberts. 2010. Subjects, tense and verb-movement. In T. Biberauer, A. Holmberg, I. Roberts and M. Sheehan (Eds.) Parametric Variation: Null Subjects in Minimalist Theory. Cambridge: Cambridge University Press. pp. 263-303.

Botha, M. and J. Oosthuizen. 2009. Die struktuur van die linker-sinsgrens in Afrikaans. Stellenbosch Papers in Linguistics Plus 37. 1-68.

Chomsky, N. 1981. Lectures on Government and Binding. Dordrecht: Foris.

Chomsky, N. 1982. Some Concepts and Consequences of the Theory of Government and Binding. Cambridge, Mass.: MIT Press.

Chomsky, N. 1986. Barriers. Cambridge, Mass.: MIT Press.

Chomsky, N. 1995. The Minimalist Program. Cambridge, Mass.: MIT Press.

Chomsky, N. 2000. Minimalist inquiries: The framework. In R. Martin, D. Michaels and J. Uriagereka (Eds.) Step by step: Essays on Minimalist Syntax in Honour of Howard Lasnik. Cambridge, Mass.: MIT Press. pp.89-155.

Chomsky, N. 2004. Beyond explanatory adequacy. In A. Belletti (Ed.) Structures and Beyond. The Cartography of Syntactic Structures (Vol. 3). Oxford: Oxford University Press pp. 104131.

Chomsky, N. 2005a. Three factors in language design. Linguistic Inquiry 36. 1-22.

Chomsky, N. 2005b. On phases. Ms. Published in R. Freidin, C. Otero and M. Zubizuretta (Eds.). 2008. Foundational Issues in Linguistic Theory. Cambridge, Mass.: MIT Press. pp. 133166.

Chomsky, N. 2006. Approaching UG from below. Ms. Published in U. Sauerland and H-M. Gärtner (Eds.). 2007. Interfaces and Recursion = Language? New York: Mouton de Gruyter pp. 1-29. 
Cinque, G. 1977. The movement nature of left dislocation. Linguistic Inquiry 8(2). 397-412.

Cinque, G. 2002. Functional Structure in DP and IP. Oxford: Oxford University Press.

Cinque, G and L. Rizzi. 2010. The cartography of syntactic structures. In B. Heine and H. Harrog (Eds.) The Oxford Handbook of Linguistic Analysis. New York: Oxford University Press. pp. 51-65.

Cruschina, S. 2012. Focus in existential sentences. In V. Bianchi and C. Chesi (Eds.) University of Manchester Internet Celebration for Luigi Rizzi's 60th Birthday. pp. 1-31. Available online at: http://www.ciscl.unisi.it/gg60.

Drubig, H. and W. Schaffar. 2001. Focus constructions. In M. Haspelmath, E. König, W. Oesterreicher and W. Raible (Eds.) Language Typology and Language Universals: An International Handbook (Vol. 2). Berlin: Walter de Gruyter. pp. 1079-1104.

Elghariani, K. 2016. A Minimalist Analysis of Obligatory Reflexivity in Tripolian Libyan Arabic. Master's thesis, Stellenbosch University.

É. Kiss, K. 1998. Identification focus versus information focus. Language 74. 245-273.

Erteschik-Shir, N. 2007. Information Structure: The Syntax-Discourse Interface. Oxford Surveys in Syntax \& Morphology 3. Oxford: Oxford University Press.

Gundel, J. 1999. On different kinds of focus. In P. Bosch and R. van der Sandt (Eds.) Focus: Linguistic, Cognitive and Computational Perspectives. Cambridge: Cambridge University Press.

Gundel, J. and T. Fretheim. 2004. Topic and focus. In L. Horn and G. Ward (Eds.) The Handbook of Pragmatics. Cambridge, Mass.: Basil Blackwell.

Haegeman, L. 1994. Introduction to Government \& Binding Theory ( ${ }^{\text {nd }}$ ed.). Oxford: Blackwell Publishing.

Hartmann, J. 2008. Expletives in Existentials: English there and German da. LOT Dissertation Series 181. Utrecht: LOT.

Hoekstra, E. and J-W. Zwart. 1994. De structuur van de CP. Spektator 23(3). 191-212.

Hornstein, N. 2009. A Theory of Syntax. Minimal Operations and Universal Grammar. Cambridge: Cambridge University Press.

Hornstein, N., J. Nunes and K. Grohmann. 2005. Understanding Minimalism. Cambridge: Cambridge University Press.

Kenesei, I. 2005. Focus as identification. In V. Molnaar and S. Winkler (Eds.) The Architecture of Focus. Berlin: Mouton. Available online at: http://www.nytud.hu/oszt/igazc/kenesei/ publ/keneseifocusmay.pdf. 
Marantz, A. 1995. The minimalist program. In G. Webelhuth (Ed.) Government and Binding Theory and the Minimalist Program. Oxford: Blackwell. pp. 349-382.

McFadden, T. 2007. Default case and the status of compound categories in distributed morphology. University of Pennsylvania Working Papers in Linguistics 13(1). Available online at: http://repository.upenn.edu/pwpl/vol13/iss1/18.

Meyer, J. 2015. The Grammatical Aspects of the Restrictive Relative Pronoun in Afrikaans: a Minimalist Approach. Master’s thesis, Stellenbosch University.

Msaka, P. 2014. A Minimalist Analysis of Obligatory Reflexivity in Chichewa. Master's thesis, Stellenbosch University.

Oosthuizen, J. 2013a. Obligatory Reflexivity in Afrikaans: a Minimalist Approach. PhD dissertation, Stellenbosch University.

Oosthuizen, J. 2013b. Obligatory reflexivity in a minimalsist grammar of Afrikaans. Stellenbosch Papers in Linguistics Plus 42. 205-241.

Paoli, S. 2006. The fine structure of the left periphery: COMPs and subjects. Evidence from Romance. Lingua 117(6). 1057-1079.

Radford, A. 2009. Analysing English Sentences. A Minimalist Approach. Cambridge: Cambridge University Press.

Reinhart, T. and E. Reuland. 1993. Reflexivity. Linguistic Inquiry 24(4). 657-720.

Rizzi, L. 1997. The fine structure of the left periphery. In L. Haegeman (Ed.) Elements of Grammar. Dordrecht: Kluwer. pp. 281-337.

Rizzi, G. (Ed.) 2004. The Cartography of Syntactic Structures (Vol. 2). The Structure of CP and IP. New York: Oxford University Press.

Roberts, C. 1998. Focus, the flow of information, and universal grammar. In P. Culicover and L. McNally (Eds.) The Limits of Syntax. San Diego: Academic Press. pp. 109-160.

Rochemont, M. 1986. Focus in Generative Grammar. Amsterdam: John Benjamins.

Rochemont, M. and P. Culicover. 1990. English Focus Constructions and the Theory of Grammar. Cambridge: Cambridge University Press.

Ross, J. 1967. Constraints on Variables in Syntax. PhD dissertation, Massachusetts Institute of Technology.

Shlonsky, U. 2010. The Cartographic Enterprise in Syntax. Linguistics and Language Compass 4. 417-429. 
Van Gelderen, E. 2013. Clause Structure: Key Topics in Syntax. Cambridge: Cambridge University Press.

Visser, I. 2015. A Minimalist Analysis of Obligatory Reflexivity in Mihavani. Master's thesis, Stellenbosch University.

Ward, G. and B. Birner. 2001. Discourse and information structure. In D. Schiffrin, D. Tannen and H. Hamilton (Eds.) The Handbook of Discourse Analysis. Oxford: Blackwell. pp. 119-137.

Webelhuth, G. (Ed.) 1995. Government and Binding Theory and the Minimalist Program. Oxford: Blackwell. 